\title{
A Curvature CPW-fed Ultra-Wideband Monopole Antenna on Liquid Crystal Polymer Substrate Using Flexible Characteristic
}

\author{
B. Kim ${ }^{(1)}$, S. Nikolaou ${ }^{(1)}$, G. E. Ponchak ${ }^{(2)}$, Y.-S. Kim ${ }^{(3)}$, J. Papapolymerou ${ }^{(1)}$, and \\ M. M. Tentzeris ${ }^{(1)}$ \\ (1) Georgia Institute of Technology, Atlanta, GA 30332-0250, U.S.A. \\ (2) NASA Glenn Research Center, Cleveland, OH 44135. U.S.A.
}

(3) Korea University, Seoul, Korea

\begin{abstract}
A curvature CPW-fed ultra-wideband monopole antenna on LCP substrate is proposed. The proposed antenna has good performance over the entire UWB frequency range $(3.1-10.6 \mathrm{GHz})$, which enhanced the impedance bandwidth by adding four notches on rectangular patch. It can be easily mounted in conformal shapes (e.g. cylindrical), because LCP substrate have many attractiveness, especially flexible characteristic, for use in many $\mathrm{mm}$-wave areas. The radiation patterns for both structures have similar performance to the conventional monopole antenna, because the antenna is flexed along its radiating side. The simulated peak-gain variation is less than $5 \mathrm{dBi}$ for both structure, which cover UWB frequency range.
\end{abstract}

\section{Introduction}

In recent years, coplanar waveguide (CPW)-fed monopole antennas have received much attention for Ultra-Wideband (UWB) applications [1-3] with a bandwidth between 3.1 - $10.6 \mathrm{GHz}$. The UWB communication systems require the transmission of pulses instead of modulated sine waves, ultra-wide bandwidth, omni-directional pattern, group delay, constant gain, and a linear phase response [4]. Liquid crystal polymer (LCP) is a relatively new material with excellent properties for use in high frequency circuits due to its low loss and low dielectric constant for mm-wave passive circuit and printed antennas [5]. Furthermore, LCP substrates can be used for multilayer (three-dimensional) modules that can be flexed, rolled up, and deployed for space applications as well as for conformal (e.g. cylindrical) antennas [6-8]. In this paper, we present the design of a curvature CPW-fed monopole UWB antenna on a flexible LCP substrate and investigate the effect of cylindrical flexing.

\section{Antenna Geometry and Results}

The geometry of the proposed curvature CPW-fed monopole antenna on a LCP substrate is shown in Figure 1. The antenna is mounted on a sheet of LCP printed circuit board with substrate thickness, h, of 4 mils, relative dielectric constant, $\varepsilon_{r}$, of 3.1, and a copper thickness of $18 \mu \mathrm{m}$. The total size $\left(w_{t} \times l_{t}\right)$ of the proposed antenna is $44 \times 40 \mathrm{~mm}^{2}$. The antenna consists of a CPW feeding structure and a rectangular radiating element. The $\mathrm{CPW}$ feeding structure has a signal line width, $w_{f}$, of $3 \mathrm{~mm}$ and gap, $g_{1}$, of $0.1 \mathrm{~mm}$. In addition, each finite ground structure has the area $\left(w_{g} \times l_{g}\right)$ of $17.5 \times 15 \mathrm{~mm}^{2}$. The radiating element is a rectangular patch with two rectangular notches ( 1 and 2 ) at the upper corner of the patch and two 
trapezoidal notches (3 and 4) at the bottom corner of the patch, which enhances the impedance bandwidth. In the proposed design, we modified the radiating patch and two ground planes to improve the impedance matching over the UWB frequency range. It was found that the gap $\left(g_{2}=0.4 \mathrm{~mm}\right)$ between the radiating patch and CPW ground plane is the most critical parameter in order to achieve the good impedance matching within the UWB bandwidth. Figure 2 shows the CPWfed, flexible monopole antenna mounted on a cylindrical test structure with radius, $\mathrm{r}$, of $35 \mathrm{~mm}$. Figure 3 shows the return loss for the flat and the conformal (curveshape) UWB CPW-fed monopole antenna on LCP which shows good agreement when compared to each other. The radiation characteristics of the proposed antennas were also studied. The simulated normalized far-field radiation patterns for both flat-shape and curved-shape configurations at $6 \mathrm{GHz}$ are shown in Figure 4 demonstrating omni-directional radiation in the patterns of the $\mathrm{X}-\mathrm{Z}$ plane and $\mathrm{Y}$ $\mathrm{Z}$ plane similar to that of a conventional monopole antenna. The radiation patterns at this frequency were similar to those of all frequencies in the band. The radiation pattern performance of the conformal antenna was similar to that of the flat-shaped antenna, especially in the H-plane, because the flexing is transverse to the CPW feeding line and parallel to the radiating edge of the antenna. Figure 5 shows the simulated antenna peak gain in the boresight direction versus frequency. The gain varies from 0 to $5 \mathrm{dBi}$ over the operating UWB frequency band.

\section{Conclusion}

A CPW-fed ultra-wideband monopole antenna on LCP substrate has been presented in this paper. The proposed antenna can be easily mounted in conformal (e.g. cylindrical) shapes due to the flexible properties of the LCP material. The simulated results show that the return loss for both flat shape and curve shape show good agreement over the entire UWB frequency range. For both configurations, the radiation patterns do not change significantly when the antenna is flexed along its radiating side. Finally, the radiation patterns of both designs exhibit monopole-like characteristics in the E-plane and omni-directional properties in the H-plane.

\section{Acknowledgment}

This work was supported by the Brain Korea 21 Project in 2005, Korea.

\section{References:}

[1] J. Liang, C. C. Chiau, X. Chen, and C. G. Parini, "CPW-fed circular ring monopole antenna," IEEE Antennas and Propagation Society International Sym-posium, vol. 2, pp. 500-503, Jul. 2005.

[2] Wen-Chung Liu and Ping-Chi Kao, "CPW-fed triangular monopole antenna for ultra-wideband operation," Microwave Opt. Technol. Lett., vol. 47, no. 6, pp 580-582, Dec. 2005. 
[3] Seong H. Lee, Jong K. Park, and Jung N. Lee, "A novel CPW-fed ultra-wide band antenna design," Microwave Opt. Technol. Lett., vol. 44, no. 5, pp 393396, Mar. 2005.

[4] FCC Report and Order for Part 15 Acceptance of Ultra Wideband (UWB) Systems from 3.1-10.6 GHz, FCC, Washington, DC, 2002.

[5] D. C. Thompson, O. Tantot, H. Jallageas, G. E. Ponchak, M. M. Tentzeris, and J. Papapolymerou, "Characterization of liquid crystal polymer (LCP) material and transmission lines on LCP substrates from 30-110 GHz," IEEE Trans. Microwave Theory Tech., vol. 52, no. 4, pp.1343-1352, Apr. 2004.

[6] G. DeJean, R. Bairavasubramanian, D. Thompon, G. E. Ponchak, M. M. Tentzeris, and J. Papapolymerou, "Liquid Crystal Polymer (LCP) : A new organic material for the development of multilayer dual-frequency / dualpolarization flexible antenna arrays," IEEE Antenna and Wireless Propag. Lett., vol. 4, pp. 22-26, 2005.

[7] R. W. Jacson, "Considerations in the use of coplanar waveguide for millimeter-wave integrated circuits," IEEE Trans. Microwave Theory Tech., vol. 34, pp. 1450-1456, Dec. 1986.

[8] Malek G. M. Hussain, "Theory and analysis of adaptive cylindrical array antenna for ultrawideband wireless communications," IEEE Trans. Wireless Comm., vol. 4, no. 6, pp. 3075-3038, Nov. 2005.

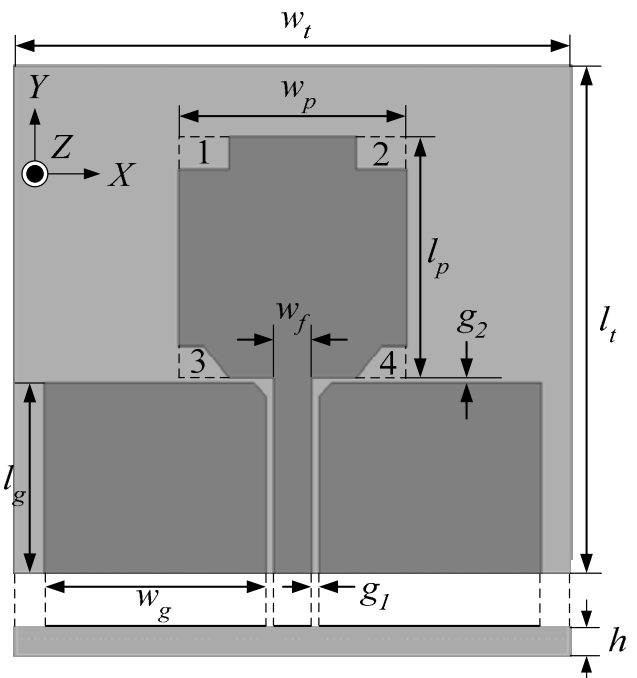

Fig. 1. Geometry of the CPW-fed monopole antenna (flat-shape).

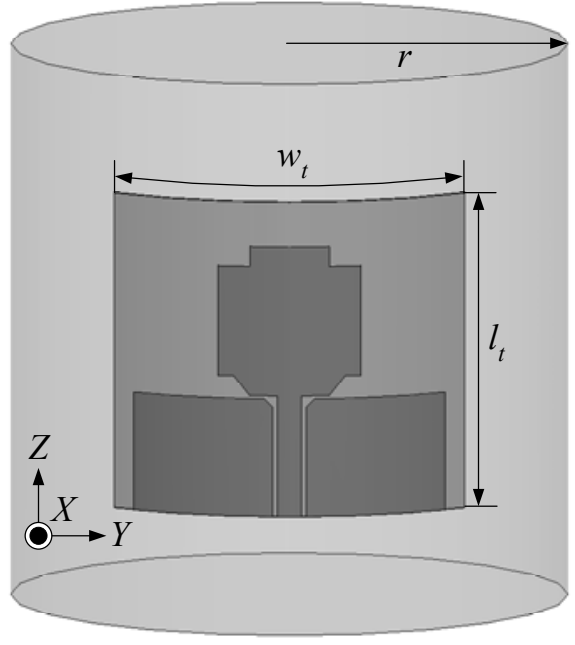

Fig. 2. Geometry of the CPW-fed monopole antenna on cylinder with radius is $35 \mathrm{~mm}$ (curve-shape). 


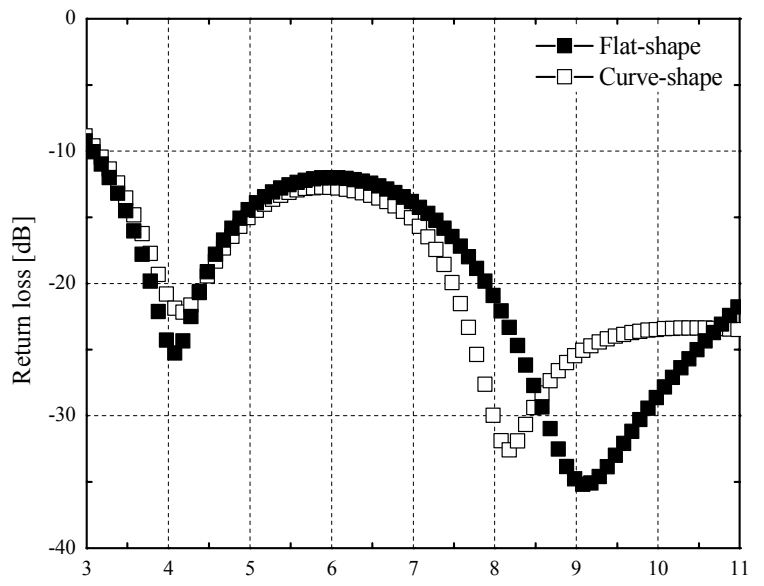

Fig. 3. Simulated return loss for both flat-shape and curve-shape.

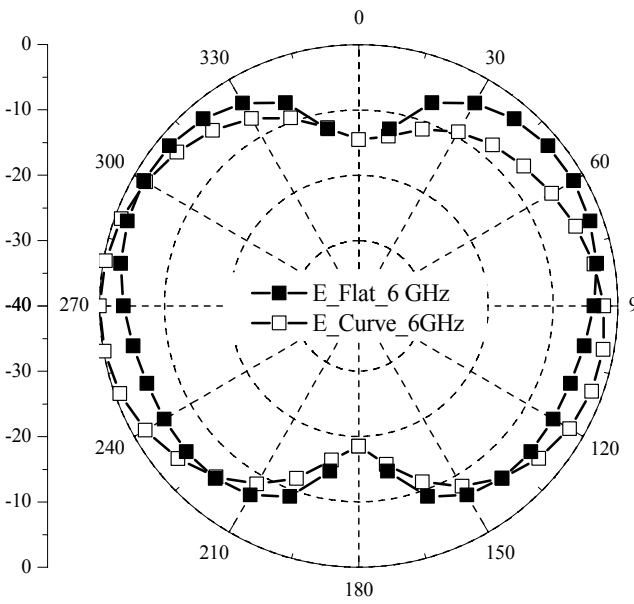

(a)

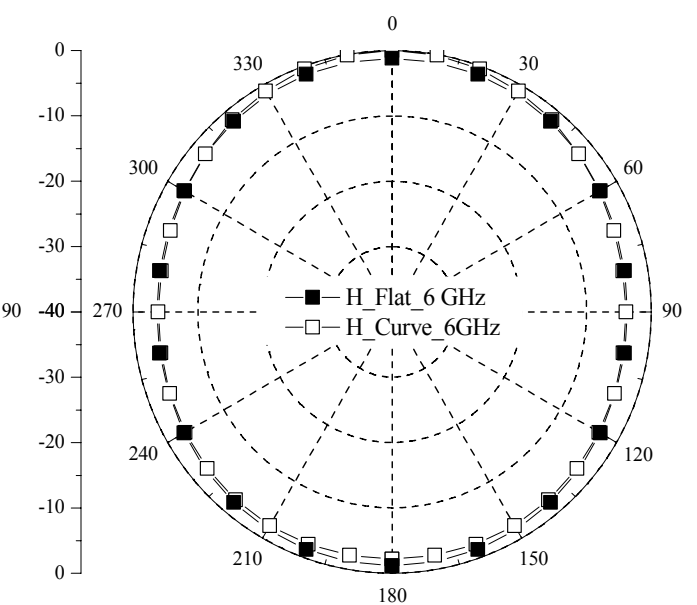

(b)

Fig. 4. Simulated radiation patterns at $6 \mathrm{GHz}$ (a) E-plane (b) H-plane.

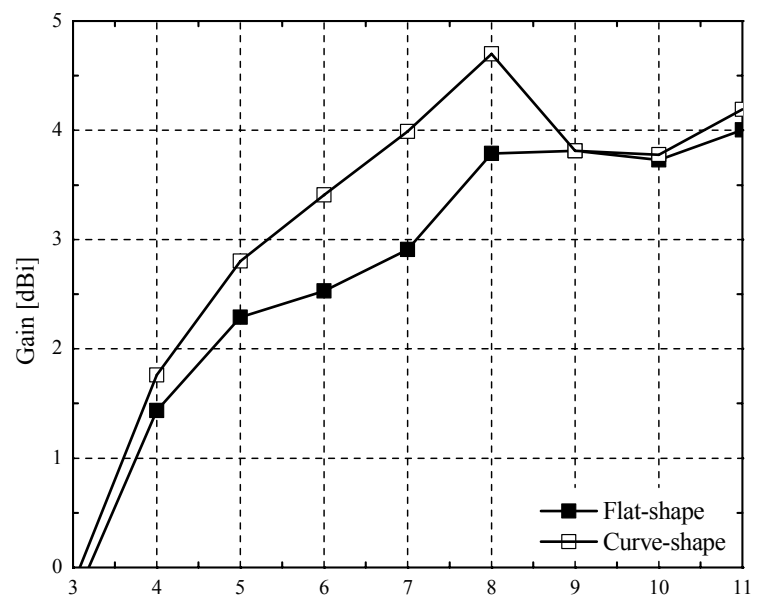

Fig. 5. Simulated peak gain of the proposed antenna. 